to allow all its best scientists to work in isolated compartments on the same problem, without access at least to other people's mistakes. Broad views of the advantages of pooling resources of inventiveness, or of pooling results, are of the utmost importance to Britain and to mankind as a whole. He therefore urged industrial firms to re-assess the work of their research departments, and where research institutes or associations for the whole of the industry do not exist, to try to devise other means for pooling with their neighbours or their competitors results of their development work.

Sir Harry remarked that some of our man-power resources are still being used wastefully, and touching on the question of taxation said that to abolish de-rating would give a great shock to industrial confidence in Britain and undo all the good resulting from the encouragement given last April to investment in plant and machinery. He urged member essociations and individual firms to make their own cases showing what would be the effect, industry by industry, of a re-introduction of full rating on top of revised valuations.

Although Sir Harry complained of the high level of employment in the Civil Service, he welcomed the endorsement by the Government and the Civil Service as a whole of the findings of Sir John Wood's Committee in the Crichel Down case, and said that it is equally important that private citizens, and especially industry, should show like consideration to Civil servants.

\section{BRITISH PHARMACEUTICAL CONFERENCE, 1954}

$\mathrm{T}$

HE ninety-first British Pharmaceutical Conference was opened at Oxford on September 13 and nearly five hundred members attended.

Dr. H. Davis, in his chairman's address, discussed the impact of National Health Service on pharmacy and outlined how the changing pattern of prescribing and dispensing demands from the pharmacist of to-day less manipulative skill but a more detailed scientific knowledge of drugs and processes than was formerly required. This changing demand is reflected. in the research papers read at the Conference.

Two of the papers are of general interest. The first, on demineralized water, shows that with correct technique demineralization of tap water by mixed anion and cation exchange resins produces a water of purity at least equal to that of distilled water B.P. The second general paper was a discussion of entrainment of liquid in distillation. It was shown that when the flow of vapour in the still-head was in streamline flow, the amount of entrainment increased with diameter of still-head and was proportional to Reynolds number.

Research of specific interest to practising pharmacists included a study of the $p H$ of the castor oil soap in the preparation of a solution of chloroxylenol in an attempt to obtain a constant product. The increased use of newer emulsifying agents is reflected in the report on polyethylene-glycol esters of cetostearyl alcohol, in which it was shown that when used alone the lower members of the series (two or four ethylene oxide units) are more effective in emulsifying arachis oil. Also in the emulsion field, an interesting point was that the addition of bentonite to certain cream bases will permit them to be autoclaved without creaming or separation of the oil.

Stability of preparations of drugs is always an important subject in pharmaceutical analysis. A quick iodometric method for estimating the hydrolysis of succinylcholine chloride, confirmed by chromatographic and biological assays, has shown that increased temperature $\left(20^{\circ} \rightarrow 37^{\circ}\right.$ C. $)$ greatly increases the instability of this drug. Since ferrous iron is more readily adsorbed than ferric iron, oxidation of ferrous gluconate solutions should be prevented; it has been found, by suitable formula. tion and storage in light, that the ferrous iron content of such a solution may increase slightly, but this is accompanied by some deposition from the solution. The most stable solution is a 10 per cent solution stored in small, completely filled containers, stabilized with $7 \cdot 5$ per cent dextrose monohydrate and stored protected from light.

It is interesting to find that the sugar coating of tablets of penicillin intended for oral use not only masks the bitter flavour but also protects the contained penicillin from external moisture, and so increases the stability that they can then be stored for two years at $25^{\circ} \mathrm{C}$.

The instability of tincture of digitalis has been a puzzle, since the frog lymph sac method of assay showed loss of potency on storage whereas the cat intravenous method did not. Fresh light has been thrown on this subject by two workers who, using a frog intravenous method, have shown that this method also indicates a drop in activity on storage and so the disagreement between the two methods of assay is not due to differences in absorption. They suggest that on storage the primary glycosides in the tincture are hydrolysed to secondary glycosides but not down to the genins.

The correlation shown between three methods of measuring pyrogenic activity-temperature rise, fall in percentage of small lymphocytes and fall in average number of lobes per neutrophil-will give pharmacologists a double confirmation of the results of pyrogen tests.

A very neat method of studying the pereutaneous absorption of substances from ointment bases has been devised. Injection of acetylcholine into a rat causes secretion of reddish-brown tears; this effect is increased by eserine, and the response can bo used for an assay of the eserine. By incorporating the eserine in an ointment base and rubbing on the skin of the rat, the amount absorbed can be ascertained.

A number of papers on the analytical aspect of research were presented, including biological and chemical assays.

In a new type of apparatus it has been shown that the rate of disinfection of solids by formaldehyde vapour is dependent on the amount of vapour per. meating the solid rather than the concentration of formaldehyde in the vapour.

The adsorption of phenol on activated charcoal, or on a precipitate caused when ferric chloride was added to the bacteriological medium used for detecting survivors from a phenol-Bact. coli mixture, showed no apparent effect on the survival-rate.

An infusion of raspberry leaves has a traditional use in giving easy and speedy parturition. Preliminary investigation into the active principles which may be responsible for this effect have led to the separation of three fractions, one a spasmolytic factor which may antagonize the stimulant effect of the other two factors, and might explain the negative 
results of clinical trials of raspberry leaf extracts. A standard method for the purification of such extracts should lead to more definite results from them.

The comparison of two types of assay for tincture of digitalis, the 18-hr. frog method and a chemical method using 3:5-dinitrobenzoic acid, has shown that the biological assay of this material is still the only sure way of ascertaining potency. Search for a means of characterizing sulphonamides by examination of their benzaldehyde and salicylaldehyde derivatives not only achieved the required results but also led to a rapid colorimetric method for the assay of sulphadimidine.

Two papers were read dealing with spectroscopy, one a general outline of infra-red techniques and the other on the determination of vitamin D.

The diverse chemical nature of synthetic analgesics led to a review of their stereochemistry, when it was found that the more analgesically active isomer of optical enantiomorphs has a spatial configuration related to that of $\mathrm{D}-(-)$-alanine. The isolation, purification and identification of the constituents of the petrol extract of serpentary formed the basis of one paper, which illustrated the vast amount of work that still remains to be done before the true nature of many of the drugs in common use is elucidated.

Two new assay techniques were reported, one for benzathine penicillin and the other for quaternary ammonium compounds.

It was argued on statistical grounds that some of the present standards for surgical dressings given in the British Pharmaceutical Codex need review, in that in some cases the exacting specifications take no account of variations which are bound to occur in manufacture and can easily be measured and limits imposed.

With the increasing use of the tablet as a convenient method of dispensing solid drugs, it is not surprising to find the symposium session of the Conf'erence devoted to tablets, when the preparation, standardization and dispensing of them were fully discussed.

\section{GIOVANNI MARIA LANCISI (1654-1720)}

$\mathrm{A}^{\mathrm{N}}$ NATOMIST, pathologist, epidemiologist, sanitarian and clinician, and one of the most advanced thinkers in the history of the medical sciences, Giovanni Maria Lancisi was born in Rome three hundred years ago, on October 26, 1654. He studied medicine at the Collegio di Sapienza, where he obtained his doctor's degree at the age of eighteen. After serving for two years as assistant physician at the Santo Spirito Hospital, he was made a canon of the Church of San Salvatore College in 1678 and devoted himself to studying the medical classics. In 1684 he was appointed professor of anatomy at the Collegio di Sapienza and thirteen years later professor of the theory and practice of medicine. A great admirer of Boerhaave, he introduced his clinical methods into medical teaching. He was physician to three successive popes: Innocent XI, Innocent XII and Clement XI. It was at Clement's request that in 1707 he wrote his monumental treatise "De subitaneis mortibus", in which he carefully records the pathological lesions of the brain and heart observed at autopsy, gives the first description of syphilis of the heart and of growths on the valves, and lists hypertrophy and dilatation of the heart as a cause of sudden death.

Lancisi's book, "De motu cordis et aneurysm. atibus" (1728), is another landmark in the history of heart disease, for it stresses the significance of heredity, syphilis and violent emotions as causes of aneurysm. In his work "De noxiis paludum effluviis eorumque remediis" (1717) he showed remarkable insight into the theory of contagion and the possible transmission of malaria by mosquitoes. He described the natural history of the mosquito, suggested repeated examination under the microscope of the blood of malarial patients, recommended with poetic fervour cinchona bark as a remedy, and pointed out the connexion between stagnant water and mosquitoes as vectors of the disease. For the prevention of malaria he advocated the draining of marshy lands and their drying up by conservation of forests. He also wrote on equine and bovine pest.

Appreciating the relation of anatomy to sculpture and painting, Lancisi, in 1691, persuaded Bernardino Genga, professor of anatomy and surgery in Rome, to publish for the use of students his studies of anatomy made from the works of the ancients, and he himself published and edited in 1714 the "Tabulae anatomicae" of Eustachius, which had lain unused in the Vatican Library for more than 150 years. In the following year he wrote "A Correct Curriculum of Medical Studies", in which he emphasized the need of a preliminary education and the value of regular visits to other medical clinics. His library of twenty thousand rare books and manuscripts (Biblioteca Lancisiana), which he presented to the Santo Spirito Hospital in 1711 for the use of young physicians and surgeons, and for the maintenance of which he left a generous legacy, represents one of the first public medical libraries.

Paradoxically, Lancisi, whose signature is writ large on so many pages of anatomy, is eponymously commemorated solely by Lancisi's nerves-striæ longitudinales on the upper surface of the corpus callosum.

A small man with lively expression and exuberant spirits, affable and diplomatic in company, Lancisi was a tremendous worker of amazing versatility, who carried on an extensive correspondence with the most famous scientists of his day. $\mathrm{He}$ died in Rome on January 21,1720 , at the age of sixty-six. In the tercentennial year of his birth he is gratefully remembered chiefly for having laid the foundation for $a_{0}$ true understanding of the pathology of the heart.

W. R. BETT

\section{SOCIETY FOR VISITING SCIENTISTS}

\section{ANNUAL REPORT FOR 1953-54}

$T$ THE annual report for 1953-54 of the Society for Visiting Scientists, the seventh report of the Society, opens with an account of the financial state of the Society, which though it is disappointing is by no means hopeless, and under the energetic direction of the honorary treasurer, Prof. A. Haddow, fresh appeals will be made to the scientific industry to support the Society (preferably by deed of covenant) and to individual scientific workers to become members.

The Society's library and lounge are available to scientific societies on payment of a small fee, and 